\title{
LA «TRASTIENDA» DEL GENIO: VELÁZQUEZ Y SU FAMILIA EN LA DÉCADA DE $1640^{1}$
}

\author{
ÁNGEL ATERIDO FERNÁNDEZ
}

\begin{abstract}
Around Diego Velázquez file various members of his family, servants, painters, artisas and officials of various types, giving us some idea of the human circle that surrounded him, as well as the connections that these people established with each other. People and business affairs from what I have come to call the «background» of Velázquez. As we interpret the content of new notary papers, which are only indications of his extra-artistic activities, the «phlegmatic» Velázquez turns out to have been meticulous in the development of this businesses.
\end{abstract}

A medida que aparece documentación sobre Velázquez y su familia directa, se va perfilando más tanto la personalidad del «pintor de pintores», como las circunstancias que rodearon su vida y sus trabajos ${ }^{2}$. Al respecto, poco se sabe de su vida económica, al margen del salario y remuneraciones que percibía como servidor real ${ }^{3}$. De hecho, los ingresos de Velázquez no se limitaron a la recepción de unos sueldos que en ocasiones se retrasaban, o bien le eran entregados en especie, siendo a veces de difícil cobro. Como para la mayoría de los españoles de su tiempo, los bienes dotales de su mujer jugaron un papel importante en el mantenimiento familiar; y no me refiero al caudal creativo que pudiera aportar Pacheco a su discípulo, sino al capital material que legó a su hija Juana, en vida y tras su fallecimiento. A esto, fue sumando otras fuentes con las que mejorar la economía familiar, sin escatimar pleitos ni querellas para ello.

El período que se pasa a analizar, se inicia precisamente con una de esas dificultades provocadas al querer materializar una recompensa otorgada por el Monarca. Felipe IV había hecho donación a su Pintor de Cámara, en 1639, de un oficio de Escribano del Repeso. No era la primera vez que se intentaba compensar al pintor con cargos administrativos, pues en 1633 ya se le había concedido el paso de una vara de alguacil ${ }^{4}$. Ante el pleito que los

1 La redacción de este artículo debe mucho a las conversaciones mantenidas con Lucía Varela, Alfonso E. Pérez Sánchez, Juan Luis Blanco Mozo y Luis Zolle, a los que agradezco sinceramente sus consejos y colaboración. Quede también constancia de mi gratitud a Salvador Salort, por su inestimable ayuda. Me resta advertir al lector del exceso de noticias, a veces mínimas, incluidas en aras de la mayor exhaustividad posible, dada la importancia del personaje. Paciencia, pues.

2 Las últimas aportaciones en este sentido son las de Peter Cherry: «Juan Bautista Martínez del Mazo, viudo de Francisca Velázquez», Archivo Español de Arte (AEA), 1990, pp. 511-527. Ibid., «New documents for Velázquez in 1620», Burlington Magazine (BM), Febrero 1991, pp. 107-115. Miguel Morán y Karl Rudolf: «Nuevos documentos en torno a Velázquez y a las colecciones reales», $A E A$, 1992, pp. 289-302. José L. Colomer: «"Dar a su magestad algo bueno": Four letters from Velázquez to Virigilio Malvezzi», BM, 1993, pp. 67-72.

3 José $M^{a}$ de Azcárate: «Noticias sobre Velázquez en la Corte», AEA, 1960, pp. 357-385. Mercedes Agulló: Más noticias sobre pintores madrileños de los siglos XVI al XVIII, Madrid, 1981, pp. 197-198. José M. Cruz Valdovinos: «Aposento, alquileres, alcabalas, aprendices y privilegios (Varios documentos y un par de retratos velazqueños inéditos)», en Velázquez y el arte de su tiempo, Madrid, 1991, pp. 91-108.

4 Varia Velazqueña, vol. II, Madrid, 1960, pp. 234-236 y 239. La relación de mercedes obtenidas por Velázquez ya la incluyó Palomino en la biografía del sevillano. Antonio Palomino: Vidas, ed. de N. Ayala, Madrid, 1986, p. 196. 
escribanos de la Cámara del Crimen le interponen al año siguiente, cuestionando la legitimidad de la cesión, Velázquez optó por vender el oficio al alguacil Luis de Peñalosa ${ }^{5}$. Se impuso por tanto, su sentido práctico, prefiriendo hacer efectiva la merced real, antes que alargarse en un interminable proceso legal. Sin embargo, no pudo eludir el farragoso engranaje administrativo, ya que en julio de 1642 , otorga un poder a procuradores para que le defiendan en dicho pleito ${ }^{6}$. Es muy posible que, dadas las trabas que implicaba el hacerse cargo de una escribanía en litigio, la venta no llegara a tener efecto, pues en el documento de poder, del que es testigo Juan de Pareja, no es mencionado Peñalosa. A falta de más datos, desconocemos en qué acabó el asunto.

Pocos años después, su yerno Juan Bautista Martínez del Mazo, resolvía, parece que con mayor éxito, un pleito con el convento de San Blas de Lerma, también por motivos relacionados indirectamente con Palacio. Mazo, en virtud de su cargo de Ujier de Cámara, cedido por Velázquez en 1634, gozaba de una casa de aposento, en un mesón propiedad de dicho convento en la calle de Atocha. La Junta de Aposento le asignó tal alojamiento el 6 de julio de 1637, aunque no parece que lo llegara a ocupar, sino que sacó rendimiento económico de él. En 1644, Mazo y el apoderado del convento llegan a un acuerdo, por el cual el pintor recibía anualmente 77 ducados a cambio de permitir el alquiler del cuarto que le correspondía ${ }^{7}$. Si bien, este convenio se debía llevar a cabo desde un principio, puesto que existen cartas de pago de Mazo al convento de Lerma desde $1641^{8}$. El concierto aquí citado, tuvo lugar para detener el pleito de despoxo que interpuso Mazo a uno de los inquilinos, como represalia por el incumplimiento del convenio. Para prevenir esto, en el nuevo documento, Martínez del Mazo estaba facultado, en caso de impago, a cobrar la deuda de los alquileres de los arrendatarios. Esta relación se prolongó diez años más, en los que se suceden las entregas de dinero al Ujier de Saleta ${ }^{9}$. En marzo de 1654, Mazo recibió un nuevo aposento, en la Morería Vieja, del que seguramente también obtuvo rendimiento, alquilándolo ${ }^{10}$.

Mientras sacaba ganancia de su aposento, Mazo residía en cuartos de alquiler más barato. Así, en 1644 arrendó a Elena Vázquez de Mendoza, viuda de Sebastián Fernández de Escobar, un cuarto bajo en la calle de San José, en la parroquialidad de San Martín, con una renta anual de 850 reales ${ }^{11}$. No hacía más que seguir el ejemplo de su suegro, quien había alquilado un cuarto en la Calle de los Señores de Luzón, en 1631, al tiempo que le estaba concedido el uso de unas casas en la calle de la Concepción Jerónima ${ }^{12}$. Lo importante del dato

5 Mercedes Agulló: Noticias sobre pintores madrileños de los siglos XVI y XVII, Granada, 1978, p. 176.

6 Archivo Histórico de Protocolos de Madrid (AHP), prot. 7.627, fols. 169-169v (21-VII-1642). Son testigos Juan de Pareja, D. Alonso Carnero y Juan Guerra Coronel. Este último, quizá emparentado con el pintor Domingo Guerra Coronel.

7 AHP: prot. 7.628, fols. 134-135 (12-III-1644).

8 AHP: prot. 7.626, fol. 247 (25-IX-1641).

9 Se han localizado veintiuna cartas de pago otorgadas por Mazo a los representantes del convento de San Blas, que abarcan desde la mencionada de 1641 hasta 1654. AHP: prot. 7.628, fols. 129 (9-III-1644), 138 (14-III1644), 449 (31-VIII-1644), 751 (10-III-1645), 941 (28-VII-1645); prot. 7.629, fols. 511 (3-I-1967), 698 (9-VIII1647); prot. 7.630, fols. 59 (6-II-1648), 409 (1-X-1648), 591 (25-II-1649), 760 (9-VII-1649); prot. 7.631, fols. 102 (19-II-1650), 414 (9-IX-1650), 582 (4-II-1651), 835 (2-IX-1651), 1.119 (15-II-1652), 1.328 (14-VIII-1652); prot. 7.632, fols. 27 (28-I-1653), 268 (12-VIII-1653), 420 (24-II-1654). Es una documentación muy repetitiva, que sólo aporta alguna información de interés en cuanto a los testigos. Destaca Benito Manuel Agüero, en la carta del 2-IX-1651; en otras se repite Matías Pastor, del que se tratará más adelante.

${ }^{10}$ Cruz Valdovinos: Op. cit., pp. 95-96. Refiere como dueño de las casas de Atocha, que abandona, a Roque de Arganda, que no figura en los protocolos antes citados.

${ }_{11}$ AHP: prot. 7.628, fol. 191 (5-IV-1644). Testigos: Juan Vázquez de Mendoza, Matías Pastor y Juan Nieto de Silva.

${ }_{12}$ Cruz Valdovinos: Op. cit., p. 94. 
no radica en si Velázquez o Mazo vivieron en tal o cual calle, sino en el provecho económico que obtenían del privilegio de aposento, recibido con sus cargos palaciegos. Como ellos, muchos de los que disfrutaban de tal prerrogativa en el Madrid de Felipe IV, aumentaban su caudal de esta manera ${ }^{13}$. En esto, se nos revela Velázquez como un cortesano más.

\section{María del Páramo. La viuda de Pacheco en Madrid}

Parece que, finalmente, el clan Velázquez-Mazo se agrupó en la casa del callejón de la Concepción Jerónima, por lo menos desde 1645. Conforme aumentaba la familia, con el nacimiento de los hijos de Mazo y Francisca Velázquez, se haría necesario un alojamiento más espacioso, por lo que pasaron a ocupar el aposento que correspondía a Velázquez. De hecho, los hijos de Mazo fueron bautizados en la vecina Parroquia de Santa Cruz, especificándose en sus partidas, a partir de 1645 — concretamente en la de Baltasar-, que el matrimonio vivía en la callejuela sin salida de la Concepción Jerónima ${ }^{14}$ (Fig. 1).

Ese mismo año llegó a dicha casa otro miembro de la familia, María del Páramo, la madre de Juana Pacheco. Francisco Pacheco había muerto en Sevilla, en noviembre de $1644{ }^{15}$, marchando después su viuda a Madrid a reunirse con su hija. La llegada de María del Páramo a la Corte se produjo antes del 3 de julio, día en que dictó testamento por encontrarse enferma ${ }^{16}$. En el documento, en el que se declara parroquiana de Santa Cruz, en Madrid, deja como heredera a Juana Pacheco y nombra por testamentarios a su hija, a Velázquez y a Martínez de Mazo. También hace mención a unas casas de las que disfrutaba en Sevilla, pertenecientes al Hospital del Amor de Dios, en cuya trasera estaban enclavadas, en la Calle de la Alameda. Había heredado el usufructo de su esposo y se lo transmitía asimismo a Juana ${ }^{17}$.

María del Páramo superó sus achaques, ya que el mes siguiente otorgaba un poder a Juan Rodríguez de Silva, el hermano de Velázquez que había acompañado a éste años antes a Madrid ${ }^{18}$, para que administrara sus bienes en la ciudad hispalense, incluidas las mencionadas casas ${ }^{19}$. Un año más tarde, por fallecimiento del hermano del pintor, daba un nuevo poder para idénticos fines a Carlos de Santa María ${ }^{20}$. En esta ocasión, se cita el nombre de los inquilinos morosos - Juan Gómez de Aguirre y Antonio García- de unas casas en la calle del Puerco.

La estancia en Madrid de la viuda de Pacheco duró unos dos años, pues murió el 12 de octubre de 1647, siendo enterrada en el Convento de la Concepción Jerónima ${ }^{21}$. Inmediatamente, Velázquez y Juana Pacheco confirmaban a Carlos de Santa María para defender sus derechos

13 José M. Cruz Valdovinos: «Música, teatro y danza en los documentos relativos al real aposento en el AHN (Felipe III y Felipe IV)», en Tiempo y espacio en el arte. Homenaje al profesor Antonio Bonet Correa, Madrid, 1994, vol. I, pp. 325-338.

${ }^{14}$ Véase Varia Velazqueña, vol. II. Allí se transcriben las partidas de bautismo conocidas de los hijos de Mazo.

${ }^{15}$ Ibidem, vol. II, p. 256

16 AHP: prot. 7.628, fols. 915-916v (3-VII-1645). Testigos: el doctor Manuel Antonio de Vargas, Juan Martínez de Moraça y Juan Romo.

17 Así consta en el testamento de Pacheco, Varia Velzqueña, vol. II, p. 247.

18 Juan Velázquez nació en Sevilla en 1601, Ibidem, vol. II, p. 214. En 1622, figurando como pintor de ymagineria, testificó en un poder otorgado por su hermano Diego a Pacheco, para el cobro de deudas. Ibidem, p. 221. En 1627 consta su presencia en Madrid, véase Cruz Valdovinos: Op. cit., 1991, p. 98.

${ }_{19}$ AHP: prot. 7.629, fol. 314 (28-VIII-1646). Testigos: Juan Bernal, Juan Martínez de Moraça y Gabriel Fanego.

AHP: prot. 7.629, fol. 708 (19-VIII-1647). Testigos: Juan Martínez de Moraça, Francisco Serrano y Francisco Álvarez.

21 Archivo de la Parroquia de Santa Cruz de Madrid. Libro 7 de Difuntos (1638-1647), fol. 417. En la partida de defunción consta que vivía en la calle de la Concepción Jerónima, en casas de Diego Velázquez de Silva. 
en su ciudad natal, como herederos de María del Páramo ${ }^{22}$. Dos meses después lo relevan por Bartolomé Jiménez, mercader de lino, para gestionar su herencia y el cobro a inquilinos ${ }^{23}$. Esta preocupación por el estado de sus cuentas, nutridas en buena parte por las rentas de alquiler, revelan la importancia que éstas debían tener en la economía familiar, así como el peso de una tradición en la forma de llevarla adelante. La sombra de Francisco Pacheco asoma de nuevo ya que, como se ve, éste ya había utilizado el arriendo de casas cedidas a él como medio alternativo de ingresos, al margen de la pintura. Los «negocios inmobiliarios» de Pacheco se centran en la sevillana Alameda de Hércules, en donde, ya en 1618 , se constata que alquiló una casa ${ }^{24}$. Quizá se trate de la misma que luego cedería a Juana como dote, al casarse con Velázquez, y para cuya gestión la pareja le otorgó poder en 1627 desde Madrid ${ }^{25}$; siendo finalmente vendidas. Las casas del Hospital del Amor de Dios, localizado en esa misma zona, eran disfrutadas por Pacheco con anterioridad a 1626, fecha en la que otorga un poder referente a ellas, al haber sido afectadas por la crecida del Guadalquivir ${ }^{26}$.

El origen de las posesiones y alquileres de Pacheco en el entorno de la Alameda, bien pudiera estar en la familia de su mujer. De hecho, fue nombrado patrón de una capellanía en la parroquia de San Martín, que tenía por dotación los alquileres de unas casas frente a los mármoles de ercules. La fundadora, Mencía Sánchez de Burgos, era la viuda de Gaspar Gutiérrez del Páramo, padre de María del Páramo. Mencía había pagado la dote de María en 1593 , declarándose su tía ${ }^{27}$. Pacheco administraba ya el patronato en 1612 y, sucesivamente, alquilará las casas para el sostenimiento de la fundación ${ }^{28}$.

De todo este cúmulo de datos, podemos extraer varias conclusiones. De una parte, el ya apuntado precedente que suponía Pacheco para Velázquez, en el modo de obtener ingresos y en su «sentido comercial» ${ }^{29}$. De otro, que las propiedades y beneficios familiares mantenían sus vínculos con Sevilla, siquiera epistolarmente. Así, uno de los hermanos del pintor, es elegido por María del Páramo para defenderlas; seguido del desconocido Carlos de Santa María y, después, de un mercader. Por cierto, que el apellido Santa María pudiera indicar el origen

${ }^{22}$ AHP: prot. 7.629, fol. 858 (20-X-1647). Testigos: Gregorio Carballo y Pacheco, Roque Pérez y Juan de Pareja. Se especifica nuevamente la necesidad de cobro de algunas casas de la calle del Puerco.

${ }^{23}$ AHP: prot. 7.629, fols. 929-930 (17-XII-1647). Testigos: Juan Martínez de Moraça, Juan de Pareja y Francisco Berxel. Éste debe ser el pintor Francisco Verges, suegro de Francisco Palacios, colaborador de Velázquez. Veáse José L. Barrio Moya: «El pintor Francisco de Palacios. Algunas noticias sobre su vida y su obra», Boletín del Seminario de Estudios de Arte y Arqueología (BSAA), 1987, pp. 425-435.

${ }^{24}$ Celestino López Martínez: Notas para la Historia del Arte. Arquitectos, escultores y pintores vecinos de Sevilla, Sevilla, 1928, p. 89.

Ibidem, pp. 210-211.

26 F. Rodríguez Marín: Francisco Pacheco, maestro de Velázquez, Madrid, 1923, p. 50. El Hospital del Amor de Dios era entonces uno de los principales arrendadores en Sevilla. Véase Juan I. Carmona García: «Caserío y arrendamientos urbanos en la Sevilla del siglo XVII», Archivo Hispalense, no 210, 1986, pp. 3-28.

27 Celestino López Martínez: Notas para la Historia del Arte. Desde Jerónimo Hernández a Martínez Montañés, Sevilla, 1929, pp. 179-180.

${ }_{28}$ Antonio Muro Orejón: Pintores y doradores. Documentos para la Historia del Arte en Andalucía, vol. VIII, Sevilla, 1935, p. 64. Celestino López Martínez: Notas para la Historia del Arte. Desde Martínez Montañés a Pedro Roldán, Sevilla, 1932, pp. 195-196. Francisco P. Cuéllar de Contreras: «Maestros pintores de la Escuela Sevillana del siglo XVII. Nuevas aportaciones documentales (I)», en Revista de Arte Sevillano, oㅡㄹ 2, 1982, pp. 17-19. En el arriendo que publicó López Martínez, se declara que las casas lindaban con las del propio Pacheco.

${ }^{29}$ Se ha visto en la relación que Pacheco hizo de las mercedes otorgadas a su yerno, una precisión más propia de un mercader que de un teórico de la liberalidad de la pintura. Juan M. Serrera: «El palacio como taller y el taller como palacio. Una reflexión más sobre Las Meninas», en Otras Meninas, Madrid, 1995, p. 240. 
converso de este personaje, que se ha llegado a sugerir del propio Velázquez ${ }^{30}$, lo que le parece relacionar con este sector de la población.

\section{Propiedades y problemas. Juana Pacheco al frente del hogar}

Mientras solucionaba a distancia los asuntos de Sevilla, la vida familiar transcurría en Madrid, atendiendo a los aspectos domésticos. El mismo día que Juana Pacheco y Velázquez autorizaban a Carlos de Santa María, asentaban en su casa como criada a una muchacha de once años, María Sánchez Calderón ${ }^{31}$.

En febrero de 1648 el patrimonio del Pintor de Cámara se vio nuevamente acrecentado, esta vez en la propia Villa y Corte, al serle cedido un terreno en la calle del Olivar ${ }^{32}$. Su propietario, el platero Francisco de Garay, le entregó el solar sobre el que pesaba un censo, que en 1639 había comprado el sevillano ${ }^{33}$. Ante el impago continuado de los réditos, desde el principio de su adquisición, en 1647 se entabló un pleito - cuyos autos se detallan en el documento de entrega-, que concluyó con el traspaso de la propiedad, a fin de saldar la deuda. De nuevo un «negocio» de Velázquez se transformó en problema, y en lugar de una cantidad periódica acabó recibiendo, al cabo del tiempo, una posesión cuya utilidad no parece muy clara. A los pocos meses, ya era citada como una corraliza perteneciente al pintor del Rey ${ }^{34}$. No es posible precisar con exactitud el lugar en que se hallaba este terreno, que limitaba por una y otra parte con Diego López, albañil, y de Don Lucas; y por las espaldas con solar de Albear. Es muy probable que se enclavara en la manzana $\mathrm{n}^{\mathbf{0}}$ 44, de la Planimetría General de Madrid (1751), ya que en ésta figuran dos fincas que fueron de Juan de Albear en la calle de Lavapiés; es decir, lindando con las traseras de las casas de la calle del Olivar ${ }^{35}$.

Sin embargo, los pleitos no abandonaron a Velázquez, pues en abril daba un nuevo poder para litigar, en un proceso por cuestiones inmobiliarias en Sevilla. Esta vez designó a Sebastián de Santa María, tal vez emparentado con su anterior apoderado, en un asunto concerniente a las casas que son del Hospital, presumiblemente el del Amor de Dios, situadas en la calle de la Garbancera ${ }^{36}$. Seguían abiertas, por tanto, las cuestiones legales en la ciudad andaluza, pese a los repetidos intentos por zanjarlas.

En tanto, Diego Velázquez emprendió su ansiado regreso a Italia en los primeros días del invierno de 1648, concretamente partió de Madrid la víspera del día de San Andrés (29 de noviembre). Dejaba a cargo del hogar a su mujer, que hasta entonces figuró en un discretísimo segundo plano. Antes de su salida, otorgó plenos poderes a Juana para hacer frente a los posibles problemas ${ }^{37}$, que no tardarían en surgir.

30 Julián Gallego: Velázquez en Sevilla, Sevilla, 1974; 2 2a ed. 1994, pp. 20-23.

31 AHP: prot. 7.629, fols. 859-860 (20-X-1647). Testigos: Gregorio Carballo y Pacheco, Roque Pérez y Juan de Pareja.

32 AHP: prot. 7.630, fols. 104-105v (14-II-1648). Testigos: Lázaro González, Francisco Miranda y Juan Martínez de Moraça.

33 AHP: prot. 5.886, 4-V-1639. Adquiere el censo de Diego de Muga, tratante. En el margen del documento aparece la firma de «Caturla», por lo que María Luisa Caturla lo localizó antes, sin llegar a publicarlo.

${ }^{34}$ Cruz Valdovinos: Op. cit., 1991, p. 95. Cita la dote de Manuela García, poseedora de unas casas frente a dichas corralizas, fechada el 16-VIII-1948.

35 Biblioteca Nacional, Madrid. Mss. 1665, Planimetría de Madrid, vol. I. Mss. 1671, Asientos de Casas de Madrid, vol. I.

${ }^{36}$ AHP: prot. 7.630, fol. 185 (28-IV-1648). Testigos: Mateo $\mathrm{gS}^{\mathrm{O}}$ (sic) de Pinilla, Juan Bautista Martínez (del Mazo) y Pedro de Careaga.

37 Agulló: Op. cit., 1978, pp. 176-177. 
En marzo de 1649, Juana firmó en su nombre una carta de pago al mercader del Rey Jerónimo de Porres, por treyntta y ocho baras de olanda a lo largo, de precio de a seis $R^{s}$ la uara para sauanas y traueseros para dormir en palacio para este pressente año ${ }^{38}$. El género le fue proporcionado a Porres por el Guardarropa Mayor, Cristóbal Tenorio y Villalta. Esta entrega estaría relacionada con las jornadas que Velázquez pasaba en el Alcázar, atareado en las obras de reforma de las piezas de oficiales, que estaban a su cargo; debía incluso de pernoctar en Palacio, ya que aún no residía en la aneja Casa del Tesoro. Al remarcar que las telas correspondían al año en curso, parece que no se esperaba una ausencia prolongada.

Los asuntos familiares fueron solventados, durante la ausencia del Pintor, en ocasiones con el auxilio de Juan Bautista Martínez del Mazo. Fue él quien concertó la dote de una de las criadas del matrimonio Velázquez, Andrea Usero, previa a su boda con el entallador Martín Gajero, en 1649; y quien la hizo efectiva, junto a su suegra ${ }^{39}$. Los enseres entregados, que junto con una cantidad en efectivo sumaban cuatrocientos ducados, eran los habituales en el ajuar de una novia: ropas de casa, vestidos, algún mueble (arcas, una cama) y utensilios de cocina. Sólo se incluyeron unas pocas pinturas: seis ramilleteros de pintura, con molduras doradas, valorados en 200 reales, y Vn quadro de pintura de ybierno (sic) del bassan, de 50 reales. La dote se terminó de pagar en octubre de ese año ${ }^{40}$. La pareja se instaló en un cuarto de las casas de aposento de Velázquez, pero los términos de su ocupación acabaron suscitando un nuevo pleito. Éste se solucionó mediante un acuerdo, en septiembre de 1650, por el cual el matrimonio pagaba a Juana Pacheco 120 reales por los quince meses de alquiler que tenían pendientes ${ }^{41}$.

Entre tanto, las propiedades sevillanas proporcionaban nuevos quebraderos de cabeza a la mujer de Velázquez. A causa de la epidemia de peste que asoló Sevilla en 1649, fallecieron tanto los inquilinos de sus casas, como los apoderados de Juana y su marido. Incluso, era necesario nombrar un nuevo clérigo para las capellanías de las que era patrona Juana Pacheco, por falta de titular. Para realizar los nuevos nombramientos precisos para salvaguardar su hacienda, no era suficiente la autorización dada por Velázquez previa a su partida, debido a defectos de forma: el documento no preveía contingencias como la delegación de poderes. Por ello, hubo de pedir una ampliación del citado poder, aceptada por D. Pedro de la Barreda, alcalde de Casa y Corte ${ }^{42}$. Con sus facultades, instituyó como su administra-

${ }^{38}$ AHP: prot. 7.630, fol. 597 (6-III-1649). Testigos: Juan Martínez de Moraça, Roque Antonio de Palacios y Alberto Vidal.

${ }_{39}$ AHP: prot. 7630. Concierto de dote, fol. 723 (22-VI-1649). Dote, fols. 725-729. Son testigos en ambos casos: Juan Martínez de Moraça, criado de la dha. Joana Pacheco, que ya había figurado como tal en documentos anteriores, Joan de horgaz, entallador que trauaxa en la Puerta del Sol, en casa de Pablo de Arroyo; y Joan de nobales, quadrista que trauaxa en la calle del Prado, en casas de Joan calbo.

40 AHP: prot. 7.630, fol. 955 (9-X-1649). Hace la entrega - 1.650 reales_, en nombre de Mazo, Juan Martínez de Moraça. Testigos: Pedro de Careaga, Pedro Pérez de Palma y Roque Antonio de Palacios.

${ }_{41}$ AHP: prot. 7.631, fol. 417 (15-IX-1650). Testigos: Roque Antonio de Palacios, Juan Martínez de Moraça y Juan Bautista Martínez del Mazo.

42 Se ha localizado un traslado de los autos, conservado en AHP: prot. 7.630, fols. 811-817. La petición de Juana se realizó el 27-VII-1649 (fols. 811-812v). Siguen las informaciones solicitadas a testigos, hechas en los dos día siguientes. Fueron citados su criado Juan Martínez de Moraça, que dijo ser de 48 años; D. Cristóbal Moreno Rejón, que bibe en la calle de la Conçeçion gerónima... en las casas donde bibe doña Juana Pacheco...; y Juan Bautista Martínez del Mazo, que dice vivir en las mismas casas que su suegra. Fue Mazo quien salió como su fiador para que el recurso fuera admitido. Moreno debía ser persona allegada, pues era padrino de María Teresa del Mazo. Varia Velazqueña, vol. II, p. 262. 
dor general en Sevilla a Juan de Villalobos, y como capellán de las obras pías fundadas por Catalina de Miranda y Mencía Sánchez, a su primo Pedro Manuel Pacheco ${ }^{43}$.

\section{El entorno de Velázquez y Mazo: Algunos nombres}

En agosto de 1651, aunque se sabe que Velázquez estaba en Madrid desde junio ${ }^{44}$, Juana Pacheco acudió nuevamente al notario en su nombre. Traspasó al pintor Matías Pastor una deuda que D. Vicente Ferrer, Caballero de Santiago y Maestro de Cámara del Rey, había contraído con la pareja en mayo, en relación con el cobro de sus salarios de Ayuda de Cámara ${ }^{45}$. Esta nueva muestra de la tardanza oficial, que muy posiblemente sea una de las causas que empujaron a Velázquez a recurrir a otros ingresos, abre una puerta para tratar del entorno inmediato a su familia. Quien adquirió el débito no es ningún desconocido para los Velázquez-Mazo, puesto que Matías Pastor de Morales aparece como testigo de alguno de los documentos aquí recogidos, por lo menos desde 1644.

La presencia de Pastor entre los allegados a la familia Velázquez, en especial a Mazo, es significativa por razones diversas. De una parte no se trata sólo de un pintor, sino que además compaginaba su actividad artística con otro oficio, puesto que era Agente de Negocios del Consejo de Santa Cruzada «en lo tocante a Indias» ${ }^{46}$. Como Velázquez y su yerno, es un pintor que consolida su posición social y económica con un cargo oficial, aunque de naturaleza bien distinta, ya que está enfocado a los negocios. Incluso, sus antecedentes familiares parecían predisponerlo a una relación, siquiera indirecta, con el sevillano. Hijo de Ana de Rómulo y de Bernal Pastor de Morales, de quien heredó el puesto administrativo, era nieto de Romolo Cincinatti y sobrino de Diego de Rómulo ${ }^{47}$. Conviene recordar que Pacheco había encabezado su lista de famosos pintores deste tiempo, favorecidos con particulares honras por la pintura precisamente con Diego de Rómulo, al que elogia especialmente por haber sido distinguido con el hábito de Cristo ${ }^{48}$. Muy probablemente coincidió con el maestro de Velázquez durante su estancia sevillana, constatada en 1610.

La relación se estrechó más entre Matías Pastor y Mazo, tal vez por su proximidad generacional. Incluso no es descartable un pupilaje común; de hecho, fue uno de los albaceas de Francisca Velázquez ${ }^{49}$. Algo podemos añadir a las breves notas sabidas acerca de Pastor. Fue el propio Martínez del Mazo quien realizó la tasación de las escasas pinturas dejadas por

${ }^{43}$ AHP: prot. 7.630, fols. 809-810v y 820-821v. 3-VIII-1649. En ambos casos son testigos Juan Martínez de Morça, Roque Antonio de Palacios y Francisco Sánchez de Escobar.

${ }^{44}$ Enriqueta Harris: «La misión de Velázquez en Italia», $A E A, 1960$, pp. 109-136.

45 Azcárate: Op. cit., p. 374. AHP: prot. 4.848, fols. 164-165 (4-V-1651). Cesión y poder de Vicente Ferrer a Diego Velázquez para que cobre de las Alcabalas de Madrid 188.796 maravedís. Id., prot. 7.631, fols. 792-793. 2-VIII-1651. Juana Pacheco vende a Matías Pastor dicho poder; son testigos Gregorio Carballo (Pacheco), el capitán Manuel de Benavides y Juan Bautista Martínez (del Mazo). Id., prot. 4.848, fols. 445-447 (14-XI-1651). Nuevo poder de Ferrer a Velázquez, por idéntico motivo. Ibidem, fols. 698-701 (8-VI-1652). En esta ocasión es Mazo quien recibe el poder para cobrar sus gaje de Ujier de Cámara lo que, a diferencia de su suegro, se produce el mismo día.

46 AHP: prot. 7.629, fol 649 (14-VI-1647). Poder de Matías Pastor a procuradores.

47 Trinidad de Antonio Sáenz: «Una familia de pintores: Rómulo Cincinato y sus hijos Francisco, Diego y Juan», en Tiempo y espacio en el arte. Homenaje al profesor Antonio Bonet Correa, Madrid, 1994, vol. II, pp. 857-866.

48 Francisco Pacheco: El Arte de la Pintura, Sevilla, 1649; ed. de Bonaventura Bassegoda, Madrid, 1990, pp. 192-193.

49 Cherry: Op. cit., p. 511. Las únicas noticias sabidas sobre Pastor, siempre como pintor, son las publicadas por M. Agulló: Más noticias sobre pintores madrileños de los siglos XVI al XVIII, Madrid, 1981, pp. 156157. Id., Documentos para la historia de la pintura española. I, Madrid, 1992, p. 94. 
su padre, Bernal ${ }^{50}$. En los autos realizados para la posterior partición de bienes se añaden nuevos cuadros, antes no inventariados, pintados por el propio Matías. Pese a intentar que le fueran adjudicados, sin incluirlos en los bienes paternos por ser de su mano, finalmente se sumaron al patrimonio ya que compró las colores, los lienços y demás neçesario... en la patria potestad ${ }^{51}$. Por esas mismas fechas, en mayo de 1643, firmó sus capitulaciones matrimoniales con Ángela Fernández del Castillo, hija de un Contador del Rey; y al año siguiente, evaluó las pinturas de María García de Bustamante ${ }^{52}$. Con su cuñado, Gabriel de Urbina, fue nombrado testamentario de Luisa del Canto, y como tales ordenaron la liquidación de sus bienes. No parece casualidad que la tasadora fuera precisamente Ana de Rómulo ${ }^{53}$.

Acentúa más la relación con el sevillano, su coincidencia con algunos allegados a Velázquez, en la almoneda del pintor Domingo Guerra Coronel, cuyo apellido también ha salido a relucir en uno de los poderes anteriormente mencionados. La tasación fue realizada por Bernabé de Contreras, con otros dos artistas cercanos al pintor de Cámara: Mazo y Angelo Nardi. Además, es de resaltar que Guerra Coronel, según reciente estudio, fue el primer poseedor de la Venus del espejo ${ }^{54}$, por lo que es figura a tener presente en futuros estudios de la estela Velazqueña. Pastor adquirió doce estampas sueltas, un grabado de Rubens y algunos pigmentos, elementos todos que aprovecharía para sus obras ${ }^{55}$.

Junto a Pastor, otro miembro de la familia Rómulo, el ya mencionado Gabriel de Urbina, también tuvo conexión con Martínez del Mazo. Juan Bautista es uno de los testigos en la entrega de la dote de su mujer, una de las hijas de Ana de Rómulo, Francisca Pastor; testimonio que repite en un poder otorgado años después por la pareja ${ }^{56}$. Urbina llegó a adquirir, hacia 1646, un oficio de Portero de Cámara del Consejo de Hacienda para el que su suegra prestó parte del dinero necesario ${ }^{57}$. Se ignora si también fue artista, de hecho su apellido nos remonta al pintor Diego de Urbina ${ }^{58}$, pero desde luego es notoria su proximidad al mundo artístico, puesto que fue testamentario del pintor Manuel de Molina, junto a Matías Pastor y el propio $\mathrm{Mazo}^{59}$. Constituye otro caso de descendiente de los pintores escurialenses, cuyos an-

${ }^{50}$ AHP: prot. 7.132, fols. 501-510v. Bernal falleció el 15-VIII-1642. La tasación de pinturas se llevó a cabo el 22-VIII-1642.

51 AHP: prot. 7.133, fol 281 (30-V-1643). Las pinturas son una Historia del Rey Ciro, La Concepción de la Virgen, Anunciación, Nacimiento, Adoración de los Reyes, Seis fruteros, El Martirio de Santa Bárbara, San Jerónimo y Dos sobreventanas de tema ignorado. Fueron tasadas por Luis Fernández, actuando Mazo como testigo; Ibidem, fol. 280 (6-VI-1643).

${ }_{52}$ AHP: prot. 7.862, fol. 30 (27-V-1643). Prot. 7.134, fol. 219 (11-IX-1644). En la tasación consta que Pastor vivía en la calle de la Ballesta a los Basilios.

53 AHP: prot. 7.134, fols. 344-347 (22-XII-1644). Agulló: Op. cit., 1981, p. 156. Matías Fernández García: Parroquia madrileña de San Sebastián. Algunos personajes de su archivo, Madrid, 1995, p. 199. Ambos citan los documentos parroquiales y transcriben el apellido como Castro.

54 Ángel Aterido: «The first owner of the Rokeby Venus», en prensa.

55 Marqués de Saltillo: «Un pintor desconocido del siglo XVII: Domingo Guerra Coronel», Arte Español, 1944-45, pp. 43-48. Saltillo resume las escrituras de la testamentaría (AHP: prot. 6.766, fols. 427-586), omitiendo algunos datos como las cuatro onzas y media de carmín, seis de azul de Sien ${ }^{a}$ y una de Carmín de Granada que consigue Pastor (fol. 549).

A6 AHP: prot. 7.626, fols. 76-79 (7-IV-1641). Gabriel de Urbina era hijo de Pedro de Urbina y Mariana Flores. Entre los enseres hay 15 cuadros, todos de tema religioso. Son testigos Juan Bautista Martínez (del Mazo), Antonio Sánchez y Cristóbal González. Id., prot. 7.627, fol. 731 (15-X-1643).

57 AHP: prot. 7.629, fol. 12 (21-I-1646).

58 Trinidad de Antonio Sáenz: Pintura española del último tercio del siglo XVI en Madrid: Juan Fernández Navarrete, Luis de Carvajal y Diego de Urbina, Madrid, 1987, vol. II, pp. 547-558. Entre los hijos de Diego consta un Pedro, nombre del padre de Gabriel; si bien puede proceder de otra rama de la familia.

Ag Aglló: Op. cit., 1978, p. 101. Publica la partida de defunción (23-VII-1660). 
tecesores contribuyeron a ennoblecer la pintura, ya que Diego de Urbina hijo -acaso su tío- llegó a ser regidor de Madrid y rey de armas de Felipe II.

Un último nombre se entresaca de esta suma de personajes: el carpintero Martín Gajero. Ya se vio como casaba con una de las criadas de Velázquez, durante su ausencia. Este artesano pasaría a formar parte de su equipo cuando fue Aposentador de Palacio, figurando entre el personal que le acompañó en la jornada de Fuenterrabía ${ }^{60}$. Que era persona de confianza de la familia, lo confirma que estuviera presente a la hora de inventariar los bienes del matrimonio Velázquez ${ }^{61}$.

Esta densa mezcla de personas y hechos, entreteje el telón de fondo sobre el que transcurre la actividad de Diego Velázquez, durante algo más de diez años. Son los años de La Coronación de la Virgen, el Retrato de Fraga y de algunas de sus versiones más logradas de retratos de enanos, como el Sebastián de Morra. Pero, sobre todo, es la década en la que pasa a encargarse de la Superintendencia de Obras y de las decoraciones del Alcázar, cuando las ocupaciones palaciegas comienzan a restarle tiempo a la pintura ${ }^{62}$. El cortesano Velázquez adopta los modos propios del estamento, se rodea de criados, se aprovecha de las prerrogativas que los cargos le proporcionan e, incluso, busca acrecentar su fortuna, salvaguardándola de los vaivenes del pago de sus gajes. En su círculo inmediato se ven análogos casos de promoción social, no tan deslumbrantes como el suyo, a través de empleos en los órganos de la administración, caso de Pastor o de Gabriel de Urbina; es más, encaminó en esta senda a su yerno, abriéndole las puertas de Palacio.

Al desgranar el carácter de los papeles aquí extractados, sólo indicios de sus actividades extraartísticas, el «flemático» Velázquez se nos descubre muy atento al desarrollo de sus negocios, y persistente en su defensa. Si bien el aséptico documento notarial no permite ahondar mucho en las relaciones humanas, y sólo proporciona un rastro de nombres, hemos podido vincular al pintor a alguno de ellos. Sobresale, por supuesto, la figura de su su esposa, capaz de reaccionar con la energía necesaria en su ausencia. Juana Pacheco, hubo de ser algo más que esa mujer gris que se ha venido pintando, imagen amparada por el tremendo desconocimiento que tenemos de ella. Por lo menos, y siempre ayudada por Juan Bautista Martínez del Mazo, estrechísimo colaborador en todo asunto, podemos imaginárnosla preocupada en proteger el bienestar familiar y la herencia propia.

Alrededor, desfilan familiares, sirvientes, pintores, artesanos o funcionarios de diversa índole, que dan una idea del medio que le rodeaba, así como de los diferentes nexos entablados con unos y otros. Juntos, personas y negocios, conformaban lo que he venido a llamar «la trastienda» de Velázquez. Alguno de ellos hubo de desempeñar un papel aun por esclarecer, como Domingo Guerra Coronel, o los habituales testigos de las visitas de Juana al notario, Roque Antonio de Palacios y Juan Martínez de Moraça. Queda así dibujado un panorama más rico, entrecruzado de personajes y actividades ajenas a la pintura, que contribuye a dar una visión más contrastada, y un poco más cierta, del Velázquez de la década de 1640.

${ }^{60} \quad$ Varia Velazqueña, vol. II, pp. 381-386. Los documentos fueron dados a conocer por Manuel Zarco del Valle y han sido recogidos, cruzados con otras fuentes, por M. J. García Sierra: «Velázquez, Mazo y José de Villareal, en el proceso ceremonial para los deposorios de Luis XIV y María Teresa de Austria», Anales del Instituto de Estudios Madrileños, 1995, pp. 101-118.

${ }^{61} \quad$ Varia Velazqueña, vol. II, p. 391.

62 Jonathan Brown: Velázquez, pintor y cortesano, Madrid, Alianza, 1986, pp. 169-194. 


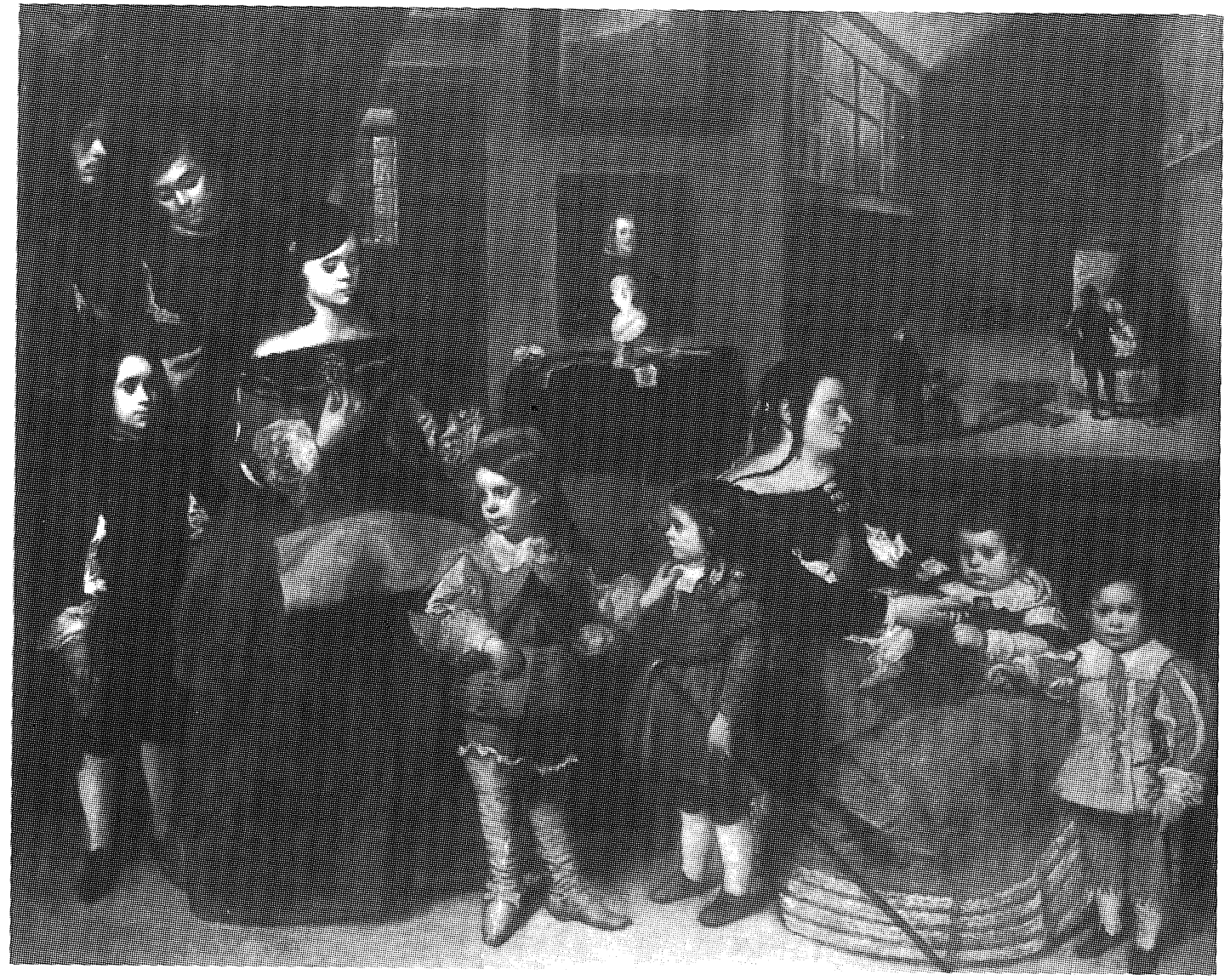

Figura 1. Juan Bautista Marínez del Mazo. La familia del pintor. Viena. Kunsthistorisches Museum. 